CBIE-LACLO 2015

Anais dos Workshops do IV Congresso Brasileiro de Informática na Educação (CBIE 2015)

\title{
As tecnologias móveis na formação docente
}

\author{
Anne Alilma Silva Souza Ferrete ${ }^{1,}$ Rodrigo Bozi Ferrete $^{2}$ \\ ${ }^{1}$ Departameto de Educação -Programa de Pós-Graduação em Educação (PPGED) - \\ NUCA-Núcleo de Comunicação e Arte (vice-líder) - Universidade Federal de Sergipe \\ (UFS) - São Cristóvão - SE - Brazil \\ ${ }^{2}$ Professor do Instituto Federal de Educação, Ciências e Tecnologia de Sergipe - IFS. \\ Doutorando em Educação - Aracaju - SE - Brazil \\ alilma.ferrete50@gmail.com, rbferrete@gmail.com
}

Formação de recursos humanos para o uso de tecnologias móveis na educação escolar

\begin{abstract}
This study aimed to understand the teacher's formation and the influence of the mobile technology in the classroom. The object of study focused on the statements of teachers with respect to use of laptop embedded in the elementary education, the E.M.E.F Pedro Izidio de Oliveira. With this research we hope to contribute for the removal of information about the options for expanding the conditions for using the laptop as a practice to be adopted increasingly by teachers in education institutions in order that teachers are responsible to train thoughtful reflective and critical. The results allow us to conclude that teachers must become aware of their training and pedagogical practice.
\end{abstract}

Resumo. O presente estudo teve como objetivo compreender a formação dos professores e a influência da tecnologia móvel em sala de aula. O objeto de estudo centrou-se nos depoimentos dos professores com relação ao uso do laptop incorporado ao ensino básico fundamental da E.M.E.F. Pedro Izídio de Oliveira. Com essa pesquisa, espera-se contribuir para o levantamento das informações sobre possibilidades de ampliação das condições para o uso do laptop como prática a ser adotada cada vez mais pelos professores das instituições de ensino, tendo em vista que os docentes são encarregados de formar sujeitos reflexivos e críticos. Os resultados obtidos permitem-nos concluir que os professores devem se conscientizar sobre sua formação e prática pedagógica.

\section{Introdução/ Justificativa}

As tecnologias digitais de informação e comunicação tem tido importância, devido a sua capacidade de transformação em todos os setores da vida, nas diversas áreas, como nas telecomunicações, no ensino, na segurança, na imprensa, na medicina etc., embora, exista polêmica quanto a possibilidade de "substituição" do homem pelo computador nos meios produtivos, devido ao grande contingente de excluídos.

A tecnologia móvel se mostra como elemento motor dos novos modos de produção, necessitando cada vez mais de indivíduos com boa formação profissional que lhe possibilite desenvolver conhecimentos teóricos, técnicos e operacionais voltados à 


\section{CBIE-LACLO 2015}

Anais dos Workshops do IV Congresso Brasileiro de Informática na Educação (CBIE 2015)

produção de bens e serviços, além da exigência cada vez maior, de formação no uso de tecnologias digitais de informação e comunicação, que demonstrem qualidade e que sejam flexíveis, eficientes e eficazes no trabalho. Conforme Silva (apud CATTANI, 1997, p. 173) "[...] equipamentos informatizados de diferentes configurações têm sido introduzidos nos mais diferentes campos da atividade humana e não só na produção industrial".

E ainda considerando que os processos de aprendizagem possam inserir indivíduos que componham as novas gerações, no mundo da cultura e da sociedade, quando estes processos direcionam para uma educação crítica e emancipatória, com uma linguagem voltada ao entendimento, capaz de garantir a esses indivíduos a formação de suas personalidades. Esse pensamento comunga com a assertiva de Boufleuer (1997), sobre o êxito na educação está relacionado ao cumprimento de suas metas gerais de transmitir tradições culturais, socializar as novas gerações, renovar solidariedades, e para isso, necessita ser concebida por uma ação comunicativa entre seus agentes, no caso os educadores, e relata que essa é a condição de possibilidade da própria experiência educativa.

Portanto, a integração da tecnologia móvel no cotidiano, e mais especificamente, no ambiente escolar, demanda certa mudança, tanto no espaço físico da escola, quanto na postura e atuação do professor no processo de ensino e aprendizagem.

Os educadores têm como tarefa, a formação das novas gerações, e, ao mesmo tempo, objetivam criar estruturas de capacitação profissional, respeitando a sua natureza e tendo consciência de que suas necessidades estão mudando. $\mathrm{O}$ sistema educativo requer profunda revisão e a escola precisa acompanhar a evolução tecnológica.

Desta forma, vale ressaltar a necessidade da formação continuada, com foco nas práticas pedagógicas que envolvam metodologias alternativas integradas ao uso da tecnologia móvel associada à atuação do professor no processo de ensino e aprendizagem, bem como na busca permanente de soluções, com o propósito de dirimi as dificuldades encontradas.

Com a chegada da tecnologia móvel e o uso, de forma potencial, como apoio pedagógico, é evidente a necessidade da apropriação tecnológica do professor, pois o uso da tecnologia móvel em sala de aula poderá proporcionar a redução dos analfabetos tecnológicos, bem como do distanciamento proporcionado pela falta de domínio e uso destas tecnologias, e é válido destacar que incluir digitalmente um indivíduo vai além de oferecer um ensino mediado pela tecnologia computacional.

O docente, ao utilizar a tecnologia móvel, poderá promover um ambiente educacional, e suscitar no aluno, uma visão crítica, o estímulo à problematização, à observação, viabilizar e ampliar a possibilidade de construção do conhecimento. Daí, ser necessário que o docente se aproprie dos recursos disponíveis através das diversas tecnologias digitais, para que possa estimular o aluno a buscar e construir seu conhecimento, desafiá-lo a (re)construir esse conhecimento e proporcionar, desse modo, o pleno desenvolvimento da criatividade e autonomia desse ator social. Faz-se necessário ter consciência de que, provavelmente o discente tenha maior apropriação tecnológica. É evidente que esse aluno tem maior facilidade de manusear as tecnologias, visto que desde cedo, está cercado por uma série de tecnologias digitais. Então, é preciso 


\section{CBIE-LACLO 2015}

Anais dos Workshops do IV Congresso Brasileiro de Informática na Educação (CBIE 2015)

que o professor saiba usar o potencial tecnológico do aluno para apoiá-lo pedagogicamente em sala de aula, e dele, poder tirar proveito.

Neste sentido, vale evidenciar o pensamento de Oliveira (2007) quando acrescenta, que é fundamental a integração das tecnologias móveis em atividades de ensino, que docentes e discentes desenvolvam trabalhos também não disciplinares, entendendo o conhecimento de forma transversal, e que sejam aproveitados as criações dos alunos em suas produções, para que seja promotora de uma educação cada vez mais inclusiva.

Diante destes pressupostos, o potencial pedagógico da tecnologia móvel ganha dimensões diferentes. Sob esta visão, justificamos a introdução da tecnologia móvel na Educação, com objetivos educacionais, tais como o incentivo à pesquisa, à leitura, entre outros, que tanto os educadores gostariam de poder promover, estimulando maiores interesses aos alunos. Desta forma, na Educação, o uso de objetos tecnológicos, cada vez mais modernos, assume outro papel, pois é através deste meio tecnológico que o aluno estará interligado aos conteúdos, ao professor e aos demais discentes quando necessário. A tecnologia digital, neste caso, torna-se uma ferramenta indispensável, uma vez que esta estará habilitada para suprir a ausência física entre o educador e educando. (FERRETE, 2010).

Diante dessas considerações, faz-se necessário repensar sobre a abordagem dos conteúdos de ensino, bem como a sua prática contextualizada e integrada ao uso da tecnologia móvel. Poderá possibilitar que os indivíduos realizem seus planos, suas pesquisas em comum acordo, ou seja, entre professores, seus pares e a equipe pedagógica de formação, de acordo com uma situação pré-definida e presente nas relações entre os educadores. Para tanto, segundo Oliveira (2004) é importante aproveitar a volatilidade, a interatividade e a flexibilidade das tecnologias digitais, potencializando práticas multiculturais, inclusivas, pensando no currículo escolar e incorporando as ações e atividades escolares previstas integradas ao uso da tecnologia digital.

Há necessidade de pensar nas diversas possibilidades de proporcionar inclusão digital desses alunos, com a integração das tecnologias móveis no ensino. Vale lembrar que é muito pouca a familiarização da maioria dos educadores com o emprego do computador ou da tecnologia móvel como instrumento educacional, enquanto constatamos a boa vontade dos discentes em se fazerem presentes, motivados com a utilização da tecnologia móvel em sala de aula, como fonte de pesquisas na Internet ou até mesmo, em produzirem trabalhos com utilização dos diversos softwares, de acordo com as exigências de suas respectivas áreas. Mediante o que foi descrito anteriormente, vale ressaltar a necessidade de refletir sobre alternativas metodológicas.

\section{Metodologia aplicada}

Definir o método é essencial para o desenvolvimento da pesquisa, a fim de que permita o alcance dos seus objetivos, conforme escolha e aplicação dos modelos mais adequados.

A natureza da pesquisa teve um caráter exploratório, de modo que permitiu uma visão mais precisa da formação e das ações dos professores, tendo em vista as mudanças 


\section{CBIE-LACLO 2015}

Anais dos Workshops do IV Congresso Brasileiro de Informática na Educação (CBIE 2015)

no cotidiano, no currículo e na cultura escolar, ocorridas diante da utilização da tecnologia móvel. E surgiu a necessidade de novos desafios com relação à formação de professores e gestores, para que o uso da tecnologia se efetivasse como apoio nas atividades pedagógicas, ou seja, a tecnologia realmente integrasse o currículo escolar, com objetivo de promover a cultura digital na instituição.

A turma observada foi de um curso à distância, de formação continuada, destinado a professores, sobre o uso de tecnologias digitais no ensino. Curso com finalidade de capacitar a equipe de gestores e docentes para o uso pedagógico das tecnologias móveis e favorecer a estruturação de redes cooperativas. O curso de 180 horas, era intercalado por encontros presenciais.

As observações realizadas na pesquisa, foram feitas com uma (01) turma, composta de professores efetivos do ensino fundamental e da gestora da E.M.E.F. Pedro Izídio de Oliveira, situada no Povoado Monte Coelho em Tobias Barreto (SE). Apesar de as observações terem sido feitas durante todo o momento do curso, neste caso, 180 horas, tanto nos períodos presenciais, como à distância, envolvendo um total de vinte e dois (22) alunos, a análise desses dados foi realizada somente após a finalização do curso, bem como a realização de entrevistas com os docentes.

Segundo Lakatos e Marconi (2010), a observação é uma técnica de coleta de dados com finalidade de obter informações, além de utilizar os sentidos na aquisição de determinados aspectos da realidade vivenciada. É necessário examinar os fatos e a observação do cotidiano escolar, importantes para validação dos dados coletado. Concluindo, o que esperamos é que, com os instrumentos anteriormente mencionados, tenhamos coletado dados não isolados, pois foi através destes que tivemos a possibilidade de visualizar a essência do problema a ser investigado.

Importante descrever o conteúdo ministrado no curso de formação dos professores. No primeiro módulo referente a apropriação tecnológica, foram apresentados aos cursistas os recursos existentes no laptop para serem trabalhados no cotidiano em sala de aula. Os softwares trabalhados no curso foram: o sistema operacional Linux; o Metasys; o KOffice composto pelo KWord, um editor de texto; o KSpread, a planilha eletrônica; e o KPresente, software para apresentações em formato de slides. Como também, algumas ferramentas educacionais disponíveis na internet, acesso aos portais, como por exemplo, o Portal do Domínio Público e Portal do Professor, portais de atividades educativas; e as Ferramentas Tux.

No segundo módulo foram trabalhadas as Tecnologias Web 2.0, ambiente de interação online que envolveu inúmeras linguagens; além da criação de conta no gmail, e de um blog.

O terceiro módulo foi trabalhado, simultaneamente, em duas vertentes: o módulo 3A com o objetivo de trabalhar com atividades pedagógicas na prática; o módulo 3B destinada aos gestores, com o objetivo de analisar quatro temas: gestão das tecnologias na escola; gestão da escola com tecnologias; análise de problemas e estratégias de solução; e plano estratégico para a construção do Projeto de Gestão Integrada de Tecnologias da (ProGITec).

No quarto módulo, foi desenvolvido um projeto contendo aspectos do currículo e o uso das tecnologias móveis presentes na escola, com base nas orientações feitas pela equipe de formadores. 


\section{CBIE-LACLO 2015}

Anais dos Workshops do IV Congresso Brasileiro de Informática na Educação (CBIE 2015)

E por fim, o desenvolvimento do ProGITec da escola, com o objetivo de integrálo ao Projeto Político Pedagógico (PPP), a fim de inserir o uso do laptop no planejamento pedagógico de todos os docentes. No final, foram realizados seminários em cada instituição, e realizado um workshop na Universidade Federal de Sergipe. Cada instituição, apresentou um banner e um objeto virtual, abordando as experiências e as pesquisas realizadas na escola com o uso do laptop e outras tecnologias móveis.

Vale destacar que as atividades foram postadas em ambiente virtual, neste caso, o ambiente E-proinfo 2.0 (http://e-proinfo.mec.gov.br/). Neste ambiente, há recursos como: agenda, tira-dúvidas, avisos, notícias, diário e biblioteca; além das ferramentas de interação e-mail: chat e fórum de discussões, de avaliação, questionários e estatísticas de atividades.

\section{Experiências vivenciadas}

No tocante à formação dos docentes da E.M.E.F. Pedro Izídio de Oliveira, houve participação da gestora, e da coordenadora pedagógica, bem como de professores efetivos do ensino fundamental. Desde o início, essa participação demarcou uma capacitação de acordo com o pensamento de Almeida \& Prado (2009) que enfatizam uma formação que contemple os diferentes profissionais da gestão, em especial os gestores e coordenadores pedagógicos.

Através das observações realizadas por um dos pesquisadores, o primeiro impasse encontrado foi a necessidade de adaptação ao novo ambiente virtual de aprendizagem. Para tal circunstância, a coordenação do curso, juntamente com os formadores, elaborou um tutorial - instrumento utilizado no processo de ensino que colaborou com o processo de aprendizagem do discente, apresentando passo a passo do funcionamento das funções e os objetivos. No entanto, essa situação persistiu com alguns cursistas no início do curso, acarretando em atrasos nas postagens das atividades, por exemplo, visto que alguns não conseguiam fazer a distância. Em conformidade, Almeida (2003) afirma que:

Participar de um curso a distância em ambientes virtuais e colaborativos de aprendizagem significa mergulhar em um mundo virtual, cuja comunicação se dá essencialmente pela leitura e interpretação de materiais didáticos textuais e hipertextuais, pela leitura da escrita do pensamento do outro, pela expressão do próprio pensamento através da escrita. Significa conviver com a diversidade e a singularidade, trocar ideias e experiências, realizar simulações, testar hipóteses, resolver problemas e criar novas situações, engajando-se na construção coletiva de uma ecologia da informação, na qual valores, motivações, hábitos e práticas são compartilhados. (ALMEIDA, 2003, p.338)

Vale ressaltar que essa foi a primeira experiência no ambiente virtual da EAD que esses educadores tiveram, e foi muito enriquecedora, pois colaborou com o 
desenvolvimento da escrita, do próprio pensamento, do comprometimento com a leitura e interpretação de textos, do planejamento do tempo dedicado aos estudos.

Em relação ao planejamento do tempo, houve maior necessidade de adaptação para cumprimento dentro do prazo, pois verificamos que no início, as atividades oferecidas eram, na maioria das vezes, em forma de recursos a serem utilizados no chat, fóruns, além das postagens de atividades. E conforme observamos, a maioria dos cursistas só respondiam as atividades, bem próximo da data limite ou não conseguiam responder dentro do prazo. Nesse aspecto, Amarilla (2011, p.61) afirma:

[...] o aluno da Educação a Distância deve possuir autonomia, autodisciplina e autodidatismo, que são atributos fundamentais para o processo de autoaprendizagem e sucesso do aluno em sua determinação. Separado fisicamente dos seus pares, dos seus professores, da sua instituição; o aluno da Educação a Distância, desse modo, exerce o monólogo interno do "conhecer". Isso significa dizer que tais atributos remetem o aluno à imagem do abandono, isto é, sozinho e isolado na tarefa de operar, sistematizar e apreender em si os caminhos do saber. (AMARILLA, 2011, p.61)

De conformidade com a autora, pode-se dizer que a formação possibilitada pelo Projeto "Um Computador por Aluno", oferecida pela equipe de formação da Universidade Federal e destinada aos educadores do Pedro Izídio de Oliveira, apresentou perspectivas de resultados significativos, pois seu corpo docente, bem como sua equipe diretiva, tiveram oportunidade de planejar e de refletir sobre a prática pedagógica e reconstruí-la para torná-la mais efetiva.

No decorrer do período observado, verificamos que estavam presentes $100 \%$ em média dos educadores; além disso, vale lembrar que no início da pesquisa, os discentes se mostraram ávidos por informações e constantemente mobilizados para questionamentos. Diante do exposto, verificamos nas observações realizadas nos momentos presenciais que a postura do professor pode influenciar, diante da visão dos alunos, no que diz respeito às potencialidades educacionais da tecnologia móvel. Conforme destaca Brito (2008):

Boa utilização do computador na escola pode propiciar a criatividade de novas formas de relação pedagógica, de novas formas de pensar o currículo e, portanto, pode também conduzir a mudanças no ambiente escolar; 2) o uso do computador na educação tem um potencial enorme, que não está diretamente relacionado à presença da máquina, mas sim do profissional, professor que firmou um compromisso com a pesquisa, com a elaboração própria, com o desenvolvimento da crítica e da criatividade, superando a cópia, o mero ensino e a mera aprendizagem. (BRITO, 2008, p.112).

Vale destacar ainda que a formação recebida contempla justamente a questão da contextualização, que possibilita ao professor reconstruir a sua própria prática 


\section{CBIE-LACLO 2015}

Anais dos Workshops do IV Congresso Brasileiro de Informática na Educação (CBIE 2015)

pedagógica, através da integração da tecnologia digital com o currículo, bem como seu planejamento.

Diante do exposto, nos encontros presenciais, antes de começar a tarefa proposta, a equipe de formação relembrava aos cursistas todo o conteúdo passado durante o módulo e debatia com os cursistas o que era necessário fazer para concluir as atividades daquele momento. Durante esses momentos presenciais, as atividades consistiam em pesquisas sobre o conteúdo e assuntos poucos explorados, durante o módulo nos fóruns, além de proporcionar oficinas práticas sobre os diversos temas para serem trabalhados em sala de aula. Os cursistas pesquisavam em vários sites. Notamos que eles coletavam e anotavam as informações dos resultados que encontravam, e acrescentavam seu ponto de vista. E conforme Bezerra, Romeiro e Rodrigues (2004), a pesquisa pode ser feita de duas formas: livre ou direcionada.

Em contrapartida, algumas das observações feitas nos dias que se seguiram e em que a tecnologia móvel foi utilizada nas atividades em sala de aula, nos momentos presenciais, permitiram constatar maior entusiasmo e participação dos cursistas; além disso, foi observado diminuição no fluxo de dispersão dos alunos no momento de realização das atividades propostas no ambiente, e apresentaram melhor aprofundamento teórico nos debates e participações nos Fóruns. Nesse sentido, foi notória a ocorrência do ambiente colaborativo de aprendizagem entre os alunos, visto que eles faziam questão de repassar para os demais suas descobertas, além dos caminhos que as conduziam para a realização das atividades. E vale ressaltar que agiram de forma resoluta nas soluções dos diversos problemas.

Isso foi repassado pelos professores cursistas aos seus alunos, conforme observamos em visita ao colégio, com intuito de observar o professor em sala de aula com seus alunos, e objetivando aproximação dessa realidade. Neste sentido, verificamos que, em relação à pesquisa livre, a professora "[...] orientava os alunos a seguirem os lugares virtuais que eles desconheciam, permitindo-lhes vislumbrar imagens criativas, assuntos diversos e situações inusitadas como o descobrimento de ideias antes desconhecidas" (ibidem, p.88). No entanto, apesar de ser nomeada de "pesquisas livres", estas sempre tinham objetivos claros, para que o aluno não procurasse fontes sem objetividade, e não se limitasse somente a buscar e aproveitar o primeiro assunto pesquisado na internet.

E no que diz respeito à pesquisa direcionada, “[...] teve o objetivo mais restrito, pois requereu do aluno, seleção de sites destinados ao conteúdo proposto, evitando assim dispersão e relaxamento quanto à proposta da professora no horário da aula" (ibidem, p.88). Foi notório que na maior parte da aula ministrada pela docente, a metodologia utilizada para pesquisa era de forma direcionada, uma vez que ela explicava qual era o tema, o que queria, e orientava os alunos pedindo que eles buscassem informações através do Google. Nos acessos aos sites a serem explorados que continham objetos virtuais de aprendizagem (OVA), foram verificados o entusiasmo, a curiosidade e autonomia, relacionados principalmente ao assunto transmitido pela professora. Uma preocupação constante da docente, com relação ao uso da internet no processo de ensino, estar vigilante e encaminhar os alunos a lerem as informações e construírem o próprio conhecimento. 


\section{CBIE-LACLO 2015}

Anais dos Workshops do IV Congresso Brasileiro de Informática na Educação (CBIE 2015)

Vale mencionar que após realização das oficinas oferecidas nas capacitações promovidas pela equipe de formação, os docentes passaram a realizar pesquisas nos sites dos objetos virtuais de aprendizagem (OVA). Neste sentido, a docente utilizava alguns objetos virtuais disponíveis em alguns sites que continham os objetos de aprendizagem, modificando consideravelmente sua metodologia, pois acessavam documentários, vídeos, jogos e atividades, de forma a complementar/revisar o conteúdo passado para o aluno, e os discentes realizavam pesquisas e atividades através desses sites. Conforme avançavam nos módulos do curso de formação continuada, os docentes passavam a produzir e utilizar seu próprio objeto virtual de aprendizagem, melhorando consideravelmente o planejamento de suas aulas e a assimilação do conteúdo por parte dos discentes.

Outro ponto importante a ser evidenciado em relação ao papel do professor frente a essa tecnologia em sala de aula, visto que, com a inserção da tecnologia computacional, conforme Mercado (2002, p.138), "[...] perde o posto de dono do saber, mas ganha uma nova e importante função, o de mediador da aprendizagem". A partir da consciência dessa função, houve possibilidade do aluno passar a ser responsável pela sua própria aprendizagem, e ter participação ativa desse processo.

Com esta perspectiva, observamos que a professora se aproximou do papel de mediadora da aprendizagem. Isso foi notado, quando a mesma ao orientar os alunos na realização da pesquisa, questionava algumas situações, a fim de provocar no aluno reflexão sobre o tema. Conforme Moran (2000 p.44), "o computador nos permite pesquisar, simular situações, testar conhecimentos específicos, descobrir novos conceitos, lugares, ideias. Produzir novos textos, avaliações, experiências". Nesta situação, a professora fez o papel de mediadora do processo de ensino e aprendizagem, permitindo que o aluno tivesse autonomia ao buscar informações para construir o conhecimento.

E em seguida, questionou os alunos sobre o que eles tinham encontrado, a fim de socializar os dados coletados, e colocando-os na lousa. A partir desta atitude de socialização, foi possível perceber uma diversidade de informações encontradas pelos alunos, como por exemplo: explorar o tema, manifestações locais, comidas específicas. Essa dinâmica permitiu que a professora não fosse a principal detentora do saber, pois, a partir do seu acompanhamento, estímulo e orientação, os alunos puderam ter acesso às informações e exercitar a capacidade de extrair pontos que, para eles, eram importantes. Neste sentido, conforme Moran (2000, p. 138), a professora "[...] passa a dirigir as pesquisas dos alunos, apontar caminhos, esclarecer dúvidas, propor projetos e, sem dúvida aprender muito mais".

Com o uso da tecnologia computacional, os alunos passaram a interagir mais. Um fato interessante foi de um aluno que, conforme a professora, apresentava dificuldade na interpretação dos textos e se recusava, muitas vezes, a lê-los. Diante da realidade vivenciada, a professora passou a solicitar que ele fizesse a leitura dos dados pesquisados e, desta forma, o aluno lia mesmo sem perceber, e contanto com as contribuições dos demais discentes. Neste sentido, paulatinamente isso deixou de ser um problema para o aluno. A estratégia, segundo Cagliari (1998), foi de trabalhar em sala de aula a leitura de maneira prazerosa sem que esse processo se tornasse árduo e chato. 


\section{CBIE-LACLO 2015}

Anais dos Workshops do IV Congresso Brasileiro de Informática na Educação (CBIE 2015)

Diante do que foi exposto, podemos concluir que a inserção da tecnologia móvel em sala de aula pode colaborar para um processo de ensino e aprendizagem mais dinâmico, que estimule o surgimento de indivíduos autônomos na construção do saber. Todavia, faz-se necessário que a docente planeje atividades diversificadas, pensando em obter resultados significativos. Todavia, foram detectadas também potencialidades do desenvolvimento do trabalho pedagógico utilizando o laptop, bem como maior envolvimento da docente no uso das tecnologias digitais.

\section{Considerações finais}

Em nossa pesquisa, registramos que a visão dos professores, com relação ao uso da tecnologia móvel em sala de aula, não se reveste de características especiais, porém, considera como um potencial pedagógico a ser assimilado e aproveitado para melhoria do ensino. Assim, percebemos que a professora que participou efetivamente da pesquisa, reconhece a importância e a necessidade de profundas reflexões sobre a realidade e suas práticas, em relação ao que os demais educadores da escola vivenciam atualmente.

Constatamos que os alunos, mostraram-se plenamente receptivos ao uso da tecnologia e levantamos a hipótese de que os conteúdos reforçados com o uso do laptop foram mais bem assimilados. Constatamos também que a utilização da tecnologia digital de informação e comunicação promoveu maior interação entre os alunos da turma, e entre a professora e os alunos, visto que eles se ajudaram tanto na busca de informações, como na apropriação tecnológica. Isto foi observado em todas as atividades que tinham como apoio pedagógico o uso do laptop.

Desta forma, podemos sugerir, primeiramente, que a escola proporcione mais cursos de capacitação continuada para os professores, e contribuam para utilização dos recursos tecnológicos com o uso de softwares educativos, demonstrando a utilidade da tecnologia móvel como uma ferramenta que servirá como apoio pedagógico. Conforme descrito anteriormente, esta tecnologia inserida no processo de ensino e aprendizagem, bem como a possibilidade de se montar grupos de estudos para a troca de experiências, assessoramento e suporte em relação à incorporação e utilização das tecnologias educacionais.

\section{References}

Almeida. Maria Elizabeth B. de. (2003) "Educação a distância na internet: abordagens e contribuições dos ambientes digitais de aprendizagem". Educ. Pesquisa [online]. 2003, vol.29, n.2, pp. 327-340. ISSN 1517-9702.

Almeida, Maria E. B. de and PRADO, Maria E. B. B. (2009) Formação de educadores para o uso dos computadores portáteis: indicadores de mudança na prática e no currículo. In: Conferência Internacional de Tecnologias de Informação e Comunicação na Educação, 6, Braga, 2009. “Anais ...” Braga, Portugal: Universidade do Minho.

Amarilla, Porfírio F. "Educação a distância: uma abordagem metodológica e didática a partir dos ambientes virtuais". Educ. rev. [online]. 2011, vol.27, n.2, p. 41-72. ISSN 0102-4698. 


\section{CBIE-LACLO 2015}

Anais dos Workshops do IV Congresso Brasileiro de Informática na Educação (CBIE 2015)

Bezerra, Aline Vieira; ROMEIRO, Iara Maria Moreira; RODRIGUES, Jonália Costa. A internet no ensino de línguas estrangeiras. In: MERCADO, Luís Paulo Leopoldo (orgs.). "Tendências na utilização das tecnologias e comunicação na educação". Maceió: EDUFAL, 2004.

Boufleuer, José P. (1997) "Pedagogia da ação comunicativa: uma leitura de Habermas". Ijuí, Ed. UNIJUÍ. (Coleção Educação).

Brito, Glaucia da Silva. "Educação e novas tecnologias: um re-pensar". 2.ed. Ibpex, 2008.

Cagliari, Luis Carlos. “Alfabetização sem bá-bé-bi-bó-bú”. 10 ed. São Paulo: Scipione, 1998.

Cattani, A. D. et al. (1997) “Trabalho e Tecnologia, Dicionário Crítico”, Petrópolis: Vozes.

Chizzotti, A. "Pesquisas em Ciências Humanas e Sociais”, São Paulo: Cortez, s.d.

Ferrete, Anne Alilma S. Souza. (2007) Sala de aula virtual: análise de um espaço vivido na EAD. In: França, Lilian C. Monteiro; Ferrete; Anne Alilma. S. Souza; Gouy, Guilherme B. (Orgs.). "Educação a Distância: ambientes virtuais, TIC e Universidades Abertas”. Aracaju: Criação, 2010.

Luckesi, C. Carlos. “Avaliação da aprendizagem escolar”. 11. ed. São Paulo: Cortez, 1998.

Marconi, de A.; LAKATOS, E. M. “Técnicas de pesquisa”. São Paulo: Atlas, 2010.

Mercado, Luís Paulo Leopoldo. "Novas tecnologias na educação: reflexão sobre a prática”. Maceió: EDUFAL, 2002.

Moran, José Manuel. Ensino e aprendizagem inovadores com tecnologias audiovisuais e telemáticas. In: MORAN, José Manuel. (Orgs). "Novas tecnologias e mediação pedagógica". Campinas: Papirus, 2000. (p.11-65)

Oliveira, J. M. A. (2004) "O hipertexto como imaginação do currículo e de conhecimentos produzidos na escola", Ano 2 - Voll.

Teixeira, Adriano Canabarro. "Inclusão Digital: novas perspectivas para a informática educativa”. Ijuí: Ed. Unijuí, 2010.

Valente, J. A.; MAZZONE, J. S.and BARANAUSKAS, M. C. C. A. (2007) "Aprendizagem na Era das Tecnologias Digitais: Conhecimento, trabalho na empresa e design de sistemas", São Paulo, Cortez Editora, v. 1. 271 p.

Valente, J. A.(Org.). (2003) "Formação de educadores para o uso da informática na escola”. Campinas, SP, UNICAMP/NIED. 